\title{
PREDICTION OF DEPTH TEMPERATURE OF ASPHALT LAYERS IN HOT CLIMATE AREAS
}

\author{
Nader SOLATIFAR ${ }^{1^{*} \mathbb{D}}$, Mojtaba ABBASGHORBANI ${ }^{2}$, Amir KAVUSSI $^{3}$, \\ Henrikas SIVILEVIČIUS ${ }^{4}$ \\ ${ }^{1}$ Department of Civil Engineering, Urmia University, Urmia, Iran \\ ${ }^{2}$ Consultant Engineering Office, Technical and Soil Mechanics Laboratory, Tehran, Iran \\ ${ }^{3}$ Faculty of Civil and Environmental Engineering, Tarbiat Modares University, Tehran, Iran \\ ${ }^{4}$ Department of Transport Technological Equipment, Vilnius Gediminas Technical University, Vilnius, Lithuania
}

Received 21 February 2018; accepted 08 August 2018

\begin{abstract}
In determination of flexible pavement layers moduli using Falling Weight Deflectometer (FWD), the pavement depth temperature should be determined and then the moduli should be corrected into a reference temperature. As direct measurement of pavement temperature is time consuming and is difficult to be determined in trafficked roads, some models are developed to predict temperature of asphalt layers through pavement depth, including BELLS model. The objective of this research is to determine correlation between actual measurement and prediction of temperature variations through asphalt layers with applying BELLS model. Ten new and rehabilitated pavement sites were selected in hot climate regions in Khuzestan and Kerman provinces in southern part of Iran. In typical hot summer days, pavement temperatures were measured at half and at one-third of the depth of asphalt layers and FWD testing were performed. Results indicated that a linear regression analysis of BELLS predicted temperatures versus measured values, provides very good correlation with actual field measurements of temperatures through the asphalt layers. Furthermore, predictions were more precise in rehabilitated pavements rather than in newly constructed pavements. Finally, using multi parametric linear fitting analysis, a new model was developed to accurately predict the temperature of asphalt layers in new pavements.
\end{abstract}

Keywords: asphalt layer temperature, BELLS model, Falling Weight Deflectometer (FWD), hot climate areas.

\section{Introduction}

Determination or prediction of surface and depth temperatures of asphalt pavements is necessity for pavement analysis, design and construction purposes. In laying and constructing asphalt layers, the cooling rate of the layer through its depth and the required time for compaction are determined based on the viscosity of binder in the mix, the mix temperature and environmental conditions (Vasenev et al. 2012). Surface temperature of the pavement is generally affected from solar energy absorption and reflection of the asphalt layer, and also from thermal properties of the mix (Petersen, Mahura 2012). For pavement analysis and design, it is important to know the minimum and maximum depth temperatures of the asphalt layer over the year. Maximum pavement temperature is usually determined from air temperature and also temperatures at half and at one-third of the depth of asphalt layers; while minimum pavement temperature is recorded as the mini- mum surface temperature which is typically assumed to be equal to the minimum air temperature (Everitt 2001; Korczak et al. 2012).

With the application of Falling Weight Deflectometer (FWD) on pavements, deflection is measured. Due to viscoelastic behavior of asphalt layers, this varies with varying temperature in the pavement. Hence, for pavement analysis purposes, deflection data are converted to a reference temperature using either a Mechanistic-Empirical (e.g. ELMOD method) or Empirical (e.g. AASHTO method) conversion processing. Therefore, the depth temperature of the asphalt layer should be determined when performing FWD testing. Mechanistic Empirical Pavement Design Guide (MEPDG) uses a climatic model called the Enhanced Integrated Climatic Model (EICM). This model is a one-dimensional coupled heat and moisture flow program that simulates changes in the behavior and charac-

*Corresponding author. E-mail: n.solatifar@urmia.ac.ir 
teristics of pavement materials considering climatic conditions over several years. The main purpose of EICM is to predict thermal stresses to feed into the pavement performance prediction models (ARA 2004).

Although generally temperatures predicted with the EICM model satisfy pavement design needs, there have been some errors when comparing with measured pavement temperatures. To overcome this problem, some new models were developed and validated in several climatic conditions. A one-dimensional mathematical model was developed by Gui et al. (2007), based on the fundamental energy balance to calculate the pavement surface temperature using hourly measured solar radiation, air temperature, dew-point temperature, and wind velocity data. This study evaluated the effects and sensitivities of the thermophysical properties on the pavement surface temperatures. The results indicated that both albedo and emissivity have the highest positive effects on pavement maximum and minimum temperatures, respectively; meanwhile, increasing the thermal conductivity, diffusivity, and volumetric heat capacity help in mitigating the maximum (daytime) but not the minimum (nighttime) pavement near-surface temperatures. Based on heat-transfer fundamentals, Han et al. (2011) developed an improved one-dimensional model, coupled with methods to obtain model-required climate data from available databases and optimization of site-specific pavement parameters to calculate hourly pavement temperatures. This provided a general tool for obtaining accurate hourly pavement temperatures as a function of depth at any desired pavement site for various applications, especially for calculations of pavement oxidation where accurate results are required.

In addition to conventional mixtures, Luca and Mrawira (2005) developed a new laboratory procedure for the determination of thermal properties of Superpave asphalt concrete specimens. In this study, the researchers investigated correlation between thermal and physical properties of asphalt concrete. Key physical properties tested for correlation include resilient modulus, Marshall Stability and flow, and also bulk density. They concluded that there was no correlation between asphalt concrete thermal properties and physical properties. Another attempt was done by Deluka-Tibljaš et al. (2015) to identify potentially favorable pavement surface materials that are suitable for the use on surfaces in urban areas. For this purpose, an extensive analysis of in-place material temperatures was conducted.

Finite Element Method (FEM) was utilized to model pavement temperature as a function of some other parameters. Energy exchange at the surface of newly laid asphalt pavements was modeled as a function of time and weather conditions by Wang et al. (2014). Thermodynamics analysis based on FEM was used to model and simulate the cooling process in different weather conditions. Field validation of the theoretical analysis indicated that the modeling and simulation results match the observations reasonably well. FEM was also used by Dakessian et al. (2016) to assess the benefits of asphalt solar collectors in predicting the temperature profile of the pavements.
As discussed earlier, one difficulty with analyzing asphalt pavement deflection data is the dependency of the deflection on the asphalt layer temperature. Several studies have been focused on the effect of pavement temperature on the deflection data produced by nondestructive testing devices. García and Castro (2011) investigated this effect by establishing a methodology to define the experimental pavement temperature adjustment factors for deflection. Measurements have been carried out at different temperatures on a road in Spain using the curviameter equipment. In another study, Dawson et al. (2016) presented a simplified procedure based on the Long-Term Pavement Performance (LTPP) Seasonal Monitoring Program that can be easily used to adjust the measured pavement deflection data routinely collected during FWD testing to the desired temperature.

Wang (2016) developed an infinite series solution to predict the time-dependent temperature profile within the pavement surface layer on the basis of measured pavement surface temperature data during FWD testing. The model approximates a pavement surface temperature history by using temperatures measured at different times during FWD testing. Comparison of the temperature profile predictions with the measured pavement temperatures, showed that the proposed solution can rapidly and accurately predict the transient temperature profile within the pavement surface layer during the short time period of FWD testing with limited inputs.

Manual measurement of layer depth temperature is very time consuming. This results in decreased work efficiency and safety concern to the evaluation personnel. Each temperature measurement takes at least 25 minutes. Using developed prediction BELLS model makes it possible to perform FWD testing without interruption for measuring temperature. The main objective of this study is to determine correlation between actual measurements and prediction of temperature variation through asphalt layers with applying BELLS model for new and rehabilitated pavements. Since this model has been developed based on seasonal data collected in LTPP program, most of the temperature data in developing the model belong to the rehabilitated pavements. Also, according to the model assumptions, the pavement surface temperatures in the model database were within $0{ }^{\circ} \mathrm{C}$ to $40^{\circ} \mathrm{C}$ ranges. Hence, multi parametric linear fitting (regression) statistical analysis was conducted and a new model with modifying original BELLS model was developed to accurately predict the depth temperature of asphalt layers in new pavements for hot climate areas.

\section{Determination of asphalt layer depth temperature}

There are three common methods for determining the temperature of an asphalt layer through its depth, namely; in-situ direct measurement, AASHTO method and BELLS model. In the direct measurement method, the temperature of an asphalt layer is measured using a thermometer 
at every 1 to 1.5 hours upon drilling a hole up to half depth of the layer during FWD testing. In this method, if the pavement temperature varies due to presence of clouds or shadows, additional measurements will be necessary (Inge, Kim 1995). Drilling the hole imparts some heat and for this reason temperature measurements should be conducted at least 20 minutes after drilling. On the other hand, stopping FWD testing in order to measure temperature of pavement layers will reduce the efficiency of the test. Another disadvantage of the direct measurement method is measuring temperature at a single point and extending that to a road section which results in severe uncertainties (Dynatest International A/S 2014). In addition, usually the pavement layers' thicknesses vary along the road, thus creating a hole for measuring the temperature in the middle depth of the asphalt layer resulted in another source of error. Kavussi et al. (2016) and Solatifar et al. (2017a, 2017b) used direct measurement method to determine pavement temperature during FWD testing for developing dynamic modulus master curves of asphalt layers.

For determining the temperature of an asphalt layer in AASHTO method, the pavement surface layer temperature is measured. This is determined either by measuring temperature at the depth of $25 \mathrm{~mm}$ or using FWD device measurement of infrared thermometer. In addition, the previous 5-day mean air temperature (i.e. before the FWD testing) and the total thickness of the asphalt layer are required, too. By knowing these data, the surface temperature is measured and the temperatures at half depths and the bottom of the asphalt layer are determined using the AASHTO graph (AASHTO 1993). The depth temperature of the asphalt layer in this method is defined as the average of the three above temperatures.

A notable disadvantage of AASHTO method is the climatic variations of the last five consecutive days before the testing that can affect the final temperature of the asphalt layer. Also, there is no difference between the positive temperature gradient (surface temperature greater than the depth) at the beginning of the day and the negative temperature gradient (depth temperature greater than the surface) at the end of the day (Fernando et al. 2001).

Finally, BELLS model uses the mean air temperature of the previous day, eliminating the error associated with AASHTO method of weather changes. This model was developed by Federal Highway Administration (FHWA) based on LTPP Seasonal Monitoring program (FHWA 1994). BELLS is acronym for the names of its five developers; Baltzer, Ertman, Larsen, Lukanen and Stubstad (Stubstad et al. 1994). It is described in detail as a standard method in ASTM D7228-06a:2015 (2015) and AASHTO T317:2009 (2009) standards. To predict temperature of an asphalt layer, BELLS model uses four parameters according to Eqn (1):

$$
\begin{aligned}
T_{d}= & \beta_{0}+\beta_{1} I R+[\log (d)-1.25] \\
& {\left[\beta_{2} I R+\beta_{3} T_{(1-d a y)}+\beta_{4} \sin \left(h r_{18}-15.5\right)\right]+} \\
& \beta_{5} I R \sin \left(h r_{18}-13.5\right),
\end{aligned}
$$

where: $T_{d}$ - pavement temperature at depth $d$ within the asphalt layer, ${ }^{\circ} \mathrm{C} ; I R$ - surface temperature measured from the infrared temperature gauge, ${ }^{\circ} \mathrm{C} ; d-$ depth at which the temperature is to be predicted, $\mathrm{mm} ; \mathrm{T}_{(1-d a y)}$ - average of the high and low air temperatures of the previous day, ${ }^{\circ} \mathrm{C}$; and, $h r_{18}$ - time of the day in the 24-hour system, calculated using an 18-hour asphalt temperature rise and fall times as explained by Stubstad et al. (1994). Coefficients of the two models, BELLS2 and BELLS3 are presented in Table 1 (AASHTO T317:2009).

Table 1. Coefficients of BELLS2 and BELLS3 equations

\begin{tabular}{|ccc|}
\hline Coefficient & BELLS2 & BELLS3 \\
\hline$\beta_{0}$ & +2.780 & +0.950 \\
\hline$\beta_{1}$ & +0.912 & +0.892 \\
\hline$\beta_{2}$ & -0.428 & -0.448 \\
\hline$\beta_{3}$ & +0.553 & +0.621 \\
\hline$\beta_{4}$ & +2.630 & +1.830 \\
\hline$\beta_{5}$ & +0.027 & +0.042 \\
\hline
\end{tabular}

BELLS3 is used in routine FWD testing ( 3 or 4 times loading at each point), where each loading is performed in less than 30 seconds. Therefore, the cooling of pavement surface due to shadow effects of FWD device is considered to be negligible. It should be noted that LTPP assesses the structural condition of pavements with applying 19 FWD loadings at each point. Stopping FWD at any point will take more than 3 minutes. This will reduce the surface temperature to some extent. Hence, BELLS2 model was proposed to consider the shadow effect of FWD device, too.

A comparison of BELLS model and the direct measurement method in determining the middle depth temperature of a typical sample asphalt layer taken from a general Pavement Management System (PMS) implemented by the authors is shown in Figure 1. Since it is not feasible to measure the depth temperature of any single testing point

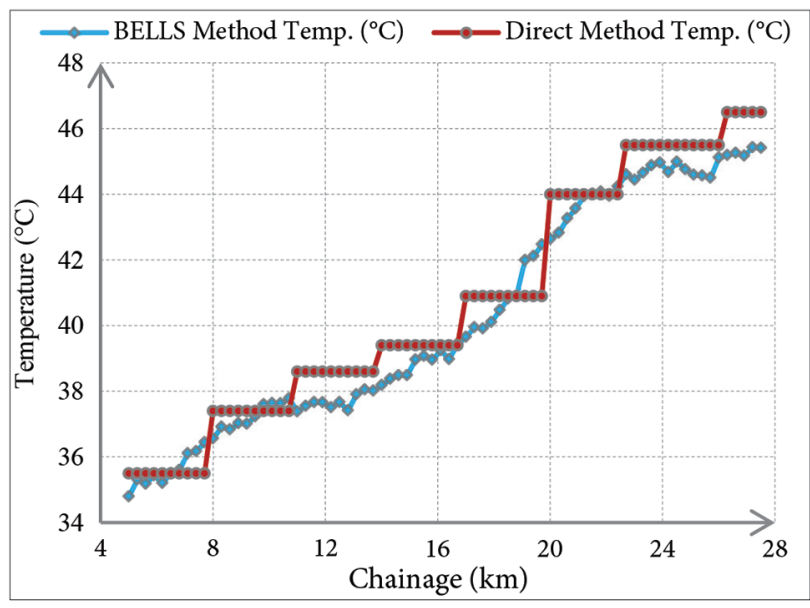

Figure 1. Layer depth temperature determination using BELLS model compared with direct measurements 


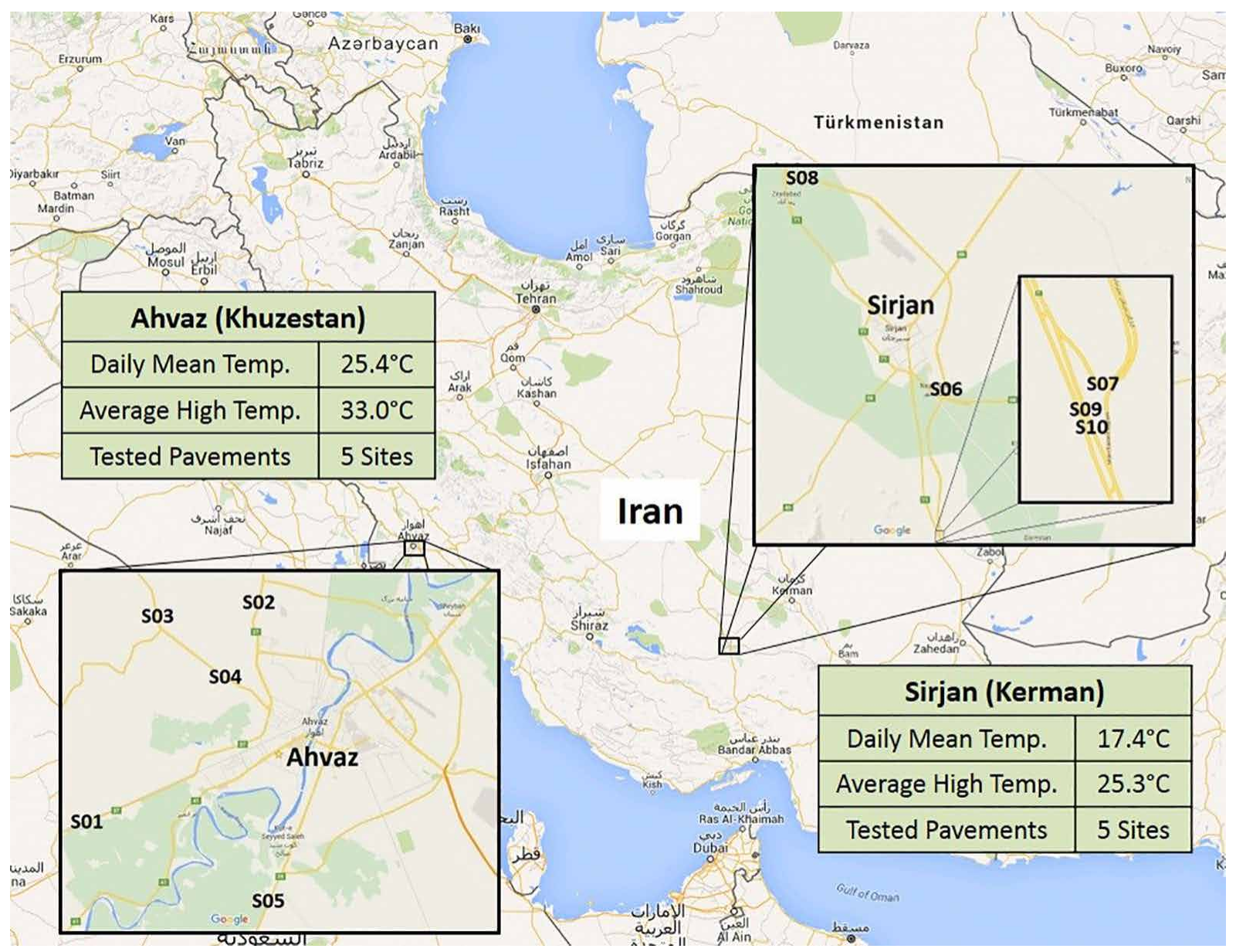

Figure 2. Location and general climatic conditions of the selected sites in Khuzestan and Kerman

of FWD using direct measurement method, the recorded temperature in a single loaded point is normally extended to all the next points. In contrast, BELLS model allows to assign a unique depth temperature at all FWD testing point due to the automatic recording of surface temperature with FWD machine. This results in time savings and the allowance of performing more tests during a day. Having good correlation with the direct measurement, BELLS model can be considered to be more advantageous rather than the other two methods. It does not require the timeconsuming works of manually measuring the depth temperature, the laborious works and the needed temperature data in AASHTO method. This results in increased accuracy and efficiency of determining the depth temperature of asphalt layers in pavement evaluation operations.

\section{Experimental program}

Ten asphalt pavement sites were selected in Khuzestan and Kerman provinces in south of Iran to determine depth temperature of asphalt layers. All these sites suffer from severe summer temperatures. According to the last sixty years climate records from Iranian Meteorological Organization, in Khuzestan, the highest air temperature varied from $28{ }^{\circ} \mathrm{C}$ in January to $54^{\circ} \mathrm{C}$ in July. In Kerman, it varied from $21^{\circ} \mathrm{C}$ in January to $42{ }^{\circ} \mathrm{C}$ in July (IRIMO 2016).
Figure 2 shows the site locations and their general climatic conditions.

Table 2 reports the general characteristics of the sites that were taken into consideration in the above two provinces. The sites were selected from different roads so that they would include pavements with different characteristics with regard to their thickness, age and previous day mean air temperature. As it can be seen in this table, for both of the new and rehabilitated pavements, the thickness of their asphalt layers varies from 75 to $400 \mathrm{~mm}$. The age of the pavement sites varied from 2 weeks to 25 years.

In these sites, temperatures at half and at one-third depths of the asphalt layers were measured manually using three digital thermometers. The surface temperature was also determined from the infrared sensor of FWD machine. The test was conducted during July and August, 2014 period. Figure 3 shows a typical FWD testing on a pavement surface and depth temperature measurements of asphalt layers. The details of configuration of the three thermometers, placed at different depths of asphalt layers is shown in Figure 4.

To consider the variations of temperature gradient during a day and also the performance of BELLS model in predicting the depth temperature of asphalt layers, site measurements were conducted at half an hour intervals during a full working day (i.e. from 6:00 a.m. to 6:00 p.m.). 
Table 2. General characteristics of the pavement sites

\begin{tabular}{|c|c|c|c|c|c|c|}
\hline Location & Road name & Site ID & Pavement type & Pavement age & $\begin{array}{c}\text { Thickness of asphalt } \\
\text { layers }(\mathrm{mm})\end{array}$ & $\mathrm{T}_{(1-d a y)}\left({ }^{\circ} \mathrm{C}\right)$ \\
\hline \multirow{5}{*}{ 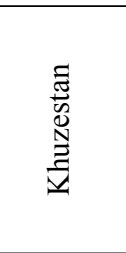 } & Ahvaz - Shirin Shahr & S01 & New & New (2 weeks) & 75 & 36.5 \\
\hline & Ahvaz - Shush & $\mathrm{S} 02$ & New & 4 years & 95 & 38 \\
\hline & Ahvaz - Hamidiyeh (1) & $\mathrm{S} 03$ & New & 5 years & 115 & 37.7 \\
\hline & Ahvaz - Hamidiyeh (2) & S04 & Rehabilitated & 10 years & 190 & 37 \\
\hline & Ahvaz - Khorramshahr & S05 & Rehabilitated & 25 years & 220 & 36 \\
\hline \multirow{5}{*}{ 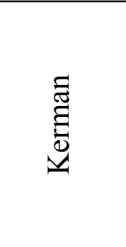 } & Sirjan - Baft & S06 & New & 6 months & 120 & 31.5 \\
\hline & Sirjan Expressway & S07 & New & 2 years & 120 & 32 \\
\hline & Sirjan-Shahr-e Babak & S08 & New Overlaid & 1 years & 145 & 33 \\
\hline & Sirjan - Bandar Abbas (1) & S09 & Rehabilitated & 15 years & 300 & 33 \\
\hline & Sirjan - Bandar Abbas (2) & S10 & Rehabilitated & 15 years & 400 & 31 \\
\hline
\end{tabular}

Table 3. Data parameters taken from selected sites and general PMS database

\begin{tabular}{|c|c|c|c|c|c|c|c|c|c|c|c|c|c|c|c|c|}
\hline \multirow{3}{*}{ Parameter } & \multicolumn{8}{|c|}{ New pavements } & \multicolumn{8}{|c|}{ Rehabilitated pavements } \\
\hline & \multicolumn{4}{|c|}{ Sites data } & \multicolumn{4}{|c|}{ General PMS data } & \multicolumn{4}{|c|}{ Sites data } & \multicolumn{4}{|c|}{ General PMS data } \\
\hline & $\mathrm{n}$ & $\min$ & $\max$ & range & $\mathrm{n}$ & $\min$ & $\max$ & range & $\mathrm{n}$ & $\min$ & $\max$ & range & $\mathrm{n}$ & $\min$ & $\max$ & range \\
\hline Surface (IR) temp. $\left({ }^{\circ} \mathrm{C}\right)$ & \multirow{4}{*}{230} & 26.1 & 55.0 & 28.9 & \multirow{4}{*}{60} & 17.4 & 55.9 & 38.5 & \multirow{4}{*}{116} & 26.0 & 51.0 & 25.0 & \multirow{4}{*}{170} & 8.0 & 60.2 & 52.2 \\
\hline Depth temp. $\left({ }^{\circ} \mathrm{C}\right)$ & & 30.0 & 58.9 & 28.9 & & 18.4 & 54.0 & 35.6 & & 30.0 & 48.0 & 18.0 & & 8.2 & 49.5 & 41.3 \\
\hline $\begin{array}{l}\text { Previous day mean air } \\
\text { temp. }\left({ }^{\circ} \mathrm{C}\right)\end{array}$ & & 31.5 & 38.0 & 6.5 & & 8.0 & 39.0 & 31.0 & & 31.0 & 37.0 & 6.0 & & 8.0 & 39.0 & 31.0 \\
\hline Thickness (mm) & & 75.0 & 145.0 & 70.0 & & 83.0 & 150.0 & 219.0 & & 190.0 & 400.0 & 210.0 & & 93.0 & 340.0 & 247.0 \\
\hline
\end{tabular}

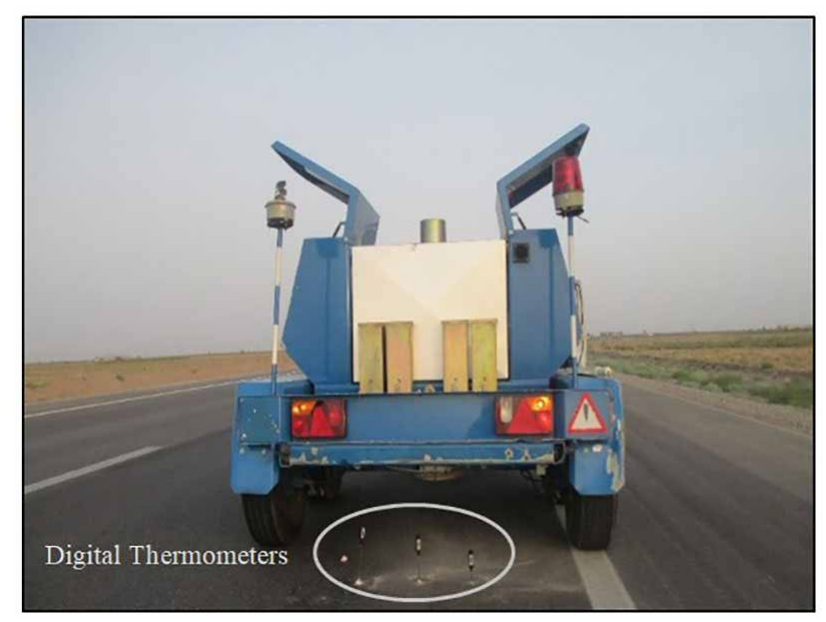

Figure 3. FWD testing and depth temperature measurements of asphalt layers on a pavement site

Therefore, 20 to 26 sets of temperature data were obtained at each testing site. To determine the mean air temperature of previous day that is required in BELLS model, minimum and maximum air temperatures of the day before testing were taken from local agencies (IRIMO 2016). In order to increase the amount of data, additional data were taken from the general PMS database that was gathered by the authors from the above two provinces. It should be noted that the total number of data used in the study were

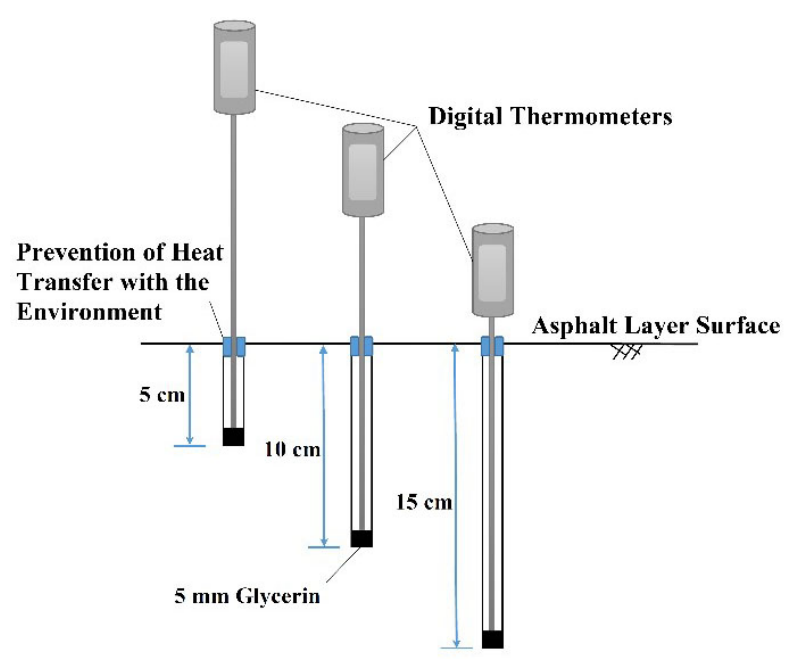

Figure 4. Detailed configuration of thermometers in depth of asphalt layers

290 sets for new pavements and 286 sets for rehabilitated pavements. Table 3 reports the two sets of the data separately for new and rehabilitated pavements.

\section{The effects of temperature variations}

Temperature variations of air, surface and half-depth of asphalt layers on sites S03, S09 and S01 are reported in Figures 5, 6 and 7, respectively. Figure 5 reports these 
in site S03 that in a newly constructed pavement. As it can be seen, with day rising, the pavement temperature rises up gradually. The pavement temperature during the day is always greater than the air temperature (i.e. due to black color of asphalt pavement that absorbs solar energy). While the asphalt depth temperature increases with increasing the air temperature, the surface temperature of the pavement exceeds that of pavement depth during midday time (i.e. from 10:00 a.m. to 15:00 p.m.). Although the surface and depth temperatures were the same at first, with increasing the air temperature and solar radiation at 10:00 a.m., the surface temperature increased due to absorption of large amounts of solar energy. The positive temperature gradient continued until 3:00 p.m. Then the surface temperature decreased (negative temperature gradient) to less than the depth temperature (due to reduced solar radiation). According to temperature data reported in Figure 5, the maximum temperatures of the surface and the depth of asphalt layers did not happen at the same time during the day which is sometimes assumed by researchers.

Figure 6 shows the temperature variations in site S09 which has rather thick asphalt layers (i.e. $300 \mathrm{~mm}$ ). Compared with site S03, it can be noted that the temperature variations of the surface and the depth of asphalt layers are appreciably greater in this pavement with thick asphalt layers. In fact, the depth temperature of the pavement at the beginning of the day was greater than the surface temperature (i.e. the air temperature was cooler than the pavement). After 9:30 a.m. this process was reversed.

At 3:00 p.m. on the day of testing, the weather condition in this site changed dramatically and for about 30 minutes, strong showers and wind occurred. As it can be seen in Figure 6, the air and surface temperatures of the asphalt layers dropped shortly due to cooling action of the short heavy rain. However, depth temperature of the asphalt layer changed rather steadily with less variations. It should be noted that these temperature variations were not included in the temperature prediction models and the data in the final analysis has been removed for this site after 3:00 p.m. Site S01 was a new pavement with $75 \mathrm{~mm}$ asphalt layer. In this site the variation of the three temperatures are rather uniform as it can be seen in Figure 7 .

\section{Evaluation of BELLS prediction model}

To evaluate BELLS model in predicting the depth temperature of asphalt layers, the measured half and one-third depth temperatures of asphalt layers were compared with the temperatures obtained from this prediction model. Using surface temperature of asphalt layer and testing time (both obtained from FWD machine), mean air temperature of the previous day and finally the desired depth, predicted temperatures were obtained. In Figures 8 and 9, directly measured temperatures with a thermometer on site and BELLS model predicted values are compared for all new and rehabilitated pavements, respectively. In these figures, Line of Equality (LOE) is shown in dashed line

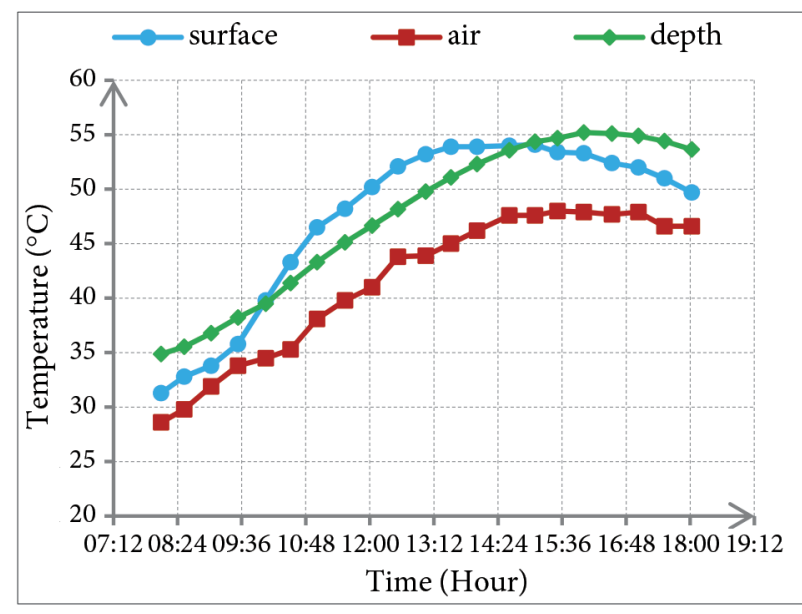

Figure 5. Air, surface and depth temperature variations in site S03 (a new pavement)

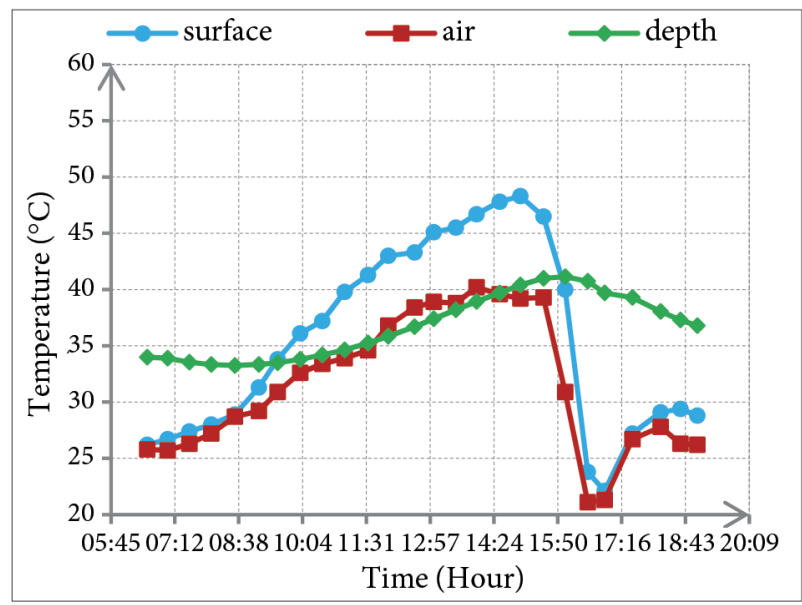

Figure 6. Air, surface and depth temperature variations in site S09 (a rehabilitated pavement)

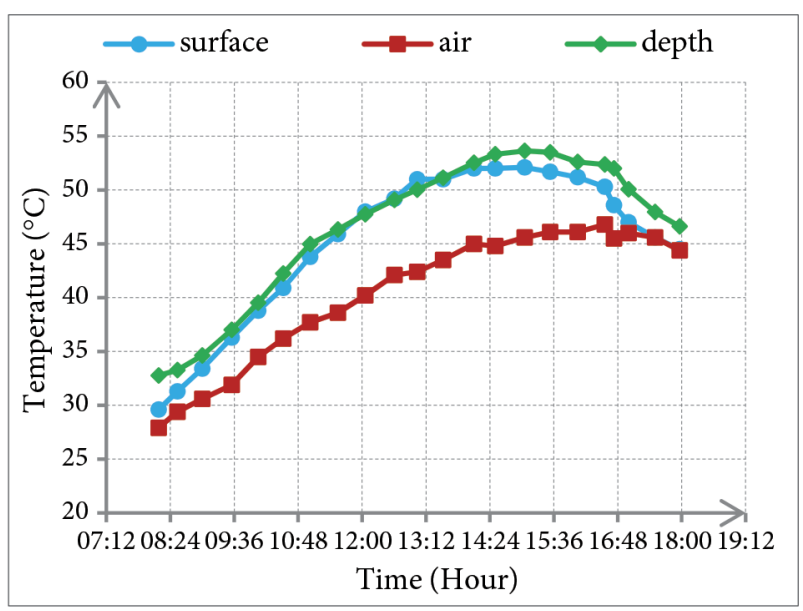

Figure 7. Air, surface and depth temperature variations in site S01 (a new pavement) 


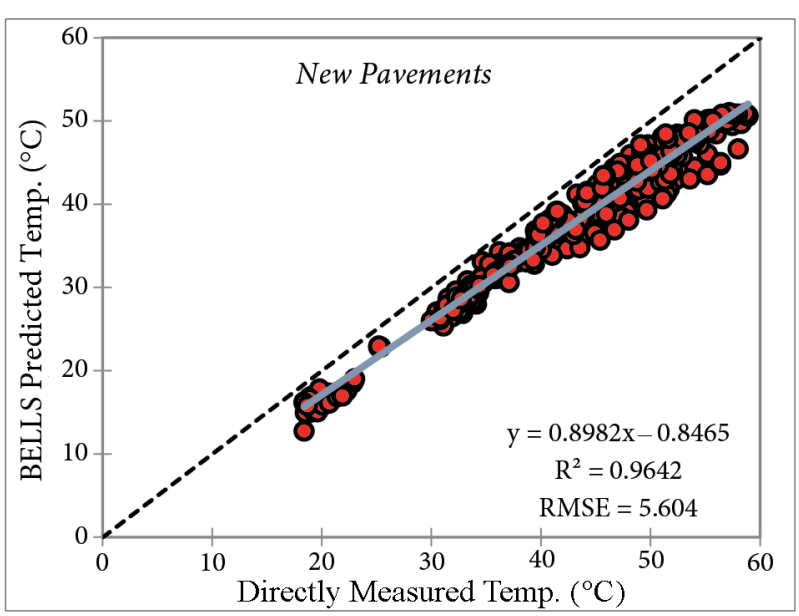

Figure 8. BELLS predicted versus directly measured temperatures in new pavements

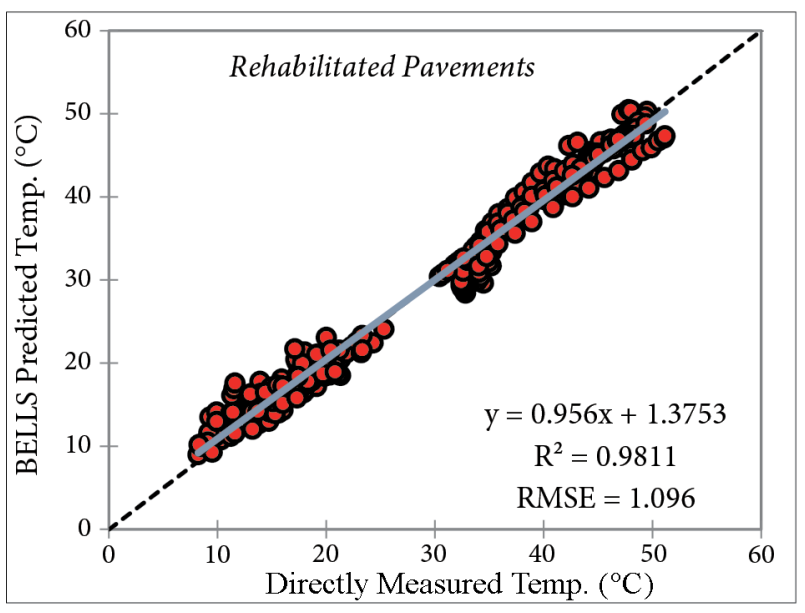

Figure 9. BELLS predicted versus directly measured temperatures in rehabilitated pavements

and a trend line was developed for predicted temperatures versus measured values.

With reference to Figure 8, depth temperatures predicted with BELLS model are slightly lower than the measured values. This trend was observed at all the new pavement sites. The slope of the trend line is less than 1 , which means that a similar trend does not exist between the predicted and the measured temperatures. Although the coefficient of determination of the trend line is high $\left(R^{2}=0.96\right)$, but it is not a suitable parameter to evaluate the accuracy of the model. Hence, to evaluate the results more accurately, the Root-Mean Square Error (RMSE) was calculated and has been shown in the figures. RMSE could be calculated according to Eqn (2):

$$
R M S E=\sqrt{\frac{1}{n} \sum_{i=1}^{n}\left(T_{i m}-T_{i p}\right)^{2}},
$$

where: $T_{i m}$ - measured temperature, ${ }^{\circ} \mathrm{C}$; and, $T_{i p}$ - predicted temperature, ${ }^{\circ} \mathrm{C}$. As it can be seen, this error in new pavements is five times greater than that of the rehabilitated ones.
For rehabilitated pavements, most of the points are placed close to the LOE, which indicates that BELLS model predicts the depth temperature with quite significant accuracy $\left(R^{2}=0.98\right)$. This is also confirmed by the low RMSE. Therefore, BELLS model could predict the depth temperature of the asphalt layers with an acceptable precision for rehabilitated pavements. Looking at the data it is noted that in rehabilitated pavements at temperatures below $30^{\circ} \mathrm{C}$, most of the predicted temperatures are greater than the measured temperatures. This trend is reversed at temperatures above $30^{\circ} \mathrm{C}$. The other reason for the differences at high temperatures may be due to temperature constraints of $0{ }^{\circ} \mathrm{C}$ to $40^{\circ} \mathrm{C}$ in developing the original BELLS model (Stubstad et al. 1994).

Overlay rehabilitated pavements are generally thicker than new pavements. Mix properties of these asphalt layers that consist of different types of aggregates and binder, age and volumetric properties, affect thermal properties of the layers. While in newly constructed pavements, various asphalt layers have similar properties. Although for new pavements it is possible to add some new parameters of thermal and volumetric properties (e.g. void in total mix (VTM) concerned with mixture type) of asphalt mixtures in the model, but using this model will be hard because of necessary laboratory tests that should be conducted on asphalt mixtures. This results in spending more time in comparison with taking direct measurements of depth temperature during FWD testing.

As discussed earlier, most of the temperature data in developing the BELLS model collected from rehabilitated in-service pavements in LTPP Program. Hence, the model doesn't work well in predicting the depth temperature for new pavements. The reason may be in different thermal behavior of newly constructed pavements in comparison with rehabilitated ones. New asphalt layers have fresh binder and are much darker rather than rehabilitated layers. During hot summer days the color is of great importance for surface temperature of asphalt layers, as a dark layer absorbs a greater portion of the solar radiation than does a light layer. On the other hand, temperature gradient is higher for new pavements, as a new paved asphalt layer transmit heat faster. So, depth temperatures are much greater in new pavements and BELLS model underpredicts these temperatures. This issue could be seen in Figure 8 . In addition, according to the model assumptions as outlined in the standard, pavement surface temperatures in the model database were within $0{ }^{\circ} \mathrm{C}$ to $40{ }^{\circ} \mathrm{C}$ ranges. Since in hot climate areas pavements experience higher temperatures, BELLS model will not be suitable for use in such pavements. Hence, a new model was developed by modifying coefficients of original BELLS model for new pavements in these climatic conditions.

\section{Developing a new model for new pavements}

As described in previous section, in case of asphalt layers in new pavements in hot climate areas, BELLS model exhibited relatively large errors in predicting depth tem- 
Table 4. Statistical parameters of new BELLS model for new pavements

\begin{tabular}{|l|c|c|c|c|c|c|c|c|c|c|}
\hline \multirow{2}{*}{$\begin{array}{c}\text { Independent } \\
\text { Parameter }\end{array}$} & \multirow{2}{*}{$\begin{array}{c}\text { Regression } \\
\text { Coefficients }\end{array}$} & $\begin{array}{c}\text { Pearson } \\
\text { Correlation }\end{array}$ & & \multicolumn{4}{|c|}{ Model 1 $\left(R^{2}=0.964\right)$} & \multicolumn{4}{c|}{ Model 2 $\left(R^{2}=0.964\right)$} \\
\cline { 5 - 12 } & & & Coefficient & $\begin{array}{c}\text { Std. } \\
\text { Error }\end{array}$ & t-value & P-value & Coefficient & $\begin{array}{c}\text { Std. } \\
\text { Error }\end{array}$ & t-value & P-value \\
\hline Constant & $\beta_{0}$ & - & 2.248 & 0.726 & 3.095 & 0.002 & 1.725 & 0.583 & 2.959 & 0.003 \\
\hline IR & $\beta_{1}$ & 0.971 & 1.010 & 0.017 & 61.036 & 0.000 & 1.022 & 0.013 & 78.475 & 0.000 \\
\hline$\left[\log _{10} d-1.25\right] \mathrm{IR}$ & $\beta_{2}$ & 0.260 & -0.392 & 0.041 & -9.519 & 0.000 & -0.419 & 0.035 & -11.998 & 0.000 \\
\hline$\left[\log _{10} d-1.25\right] \mathrm{T}(1-$ day) & $\beta_{3}$ & 0.196 & 0.471 & 0.045 & 10.509 & 0.000 & 0.491 & 0.042 & 11.793 & 0.000 \\
\hline $\begin{array}{l}{\left[\log _{10} d-1.25\right]} \\
\left.\sin \left(\mathrm{hr}_{18}-15.5\right)\right]\end{array}$ & $\beta_{4}$ & 0.583 & 1.096 & 0.909 & 1.205 & $\underline{0.229}$ & - & - & - & - \\
\hline $\sin \left(\mathrm{hr}_{18}-13.5\right) \mathrm{IR}$ & $\beta_{5}$ & 0.354 & 0.042 & 0.011 & 3.852 & 0.000 & 0.054 & 0.006 & 8.895 & 0.000 \\
\hline
\end{tabular}

peratures. To improve performance of the model in new pavements, a multi parametric linear fitting (regression) analysis was carried out in SPSS software. Multi parametric linear regression is an extension of simple linear regression. This statistical technique is used to predict the value of a variable based on the value of two or more other variables. The variable which is to be predicted, is called the dependent variable; while other variables are called independent or predictor variables. The goal of multi parametric linear regression is to model the relationship between the predictor and dependent variables.

In this analysis, the measured temperatures in the half and one-third depths of the asphalt layers were considered as dependent variables and modifications were performed on original coefficients of BELLS model. Data used in modification were limited to the six testing sites and also additional general PMS data of new asphalt pavements in this study. Independent parameters, as shown in Table 4, were extracted from BELLS model to determine coefficients of fitting model similar to standard definitions. In this table, the intercept (constant $\beta_{0}$ ) and five other coefficients of the model $\left(\beta_{1}, \beta_{2}, \beta_{3}, \beta_{4}\right.$, and $\left.\beta_{5}\right)$ were reported. These values represent the slope of the line between the predictor variable and the dependent variable.

Values of Pearson Correlation of coefficients (associated with the model) were provided in the third column as dependent parameter (measured temperature). This parameter acts very similarly to a correlation coefficient. It ranges from 0 to 1 or 0 to -1 , depending on the direction of the relationship. The closer the value is to 1 or -1 , the stronger the relationship. By comparing these coefficients, since all of them are on the 0 to 1 scale, it is possible to actually compare the variables to see which ones have the strongest relationship with the dependent variable. In this analysis, it is shown that all independent parameters are directly related to depth temperatures and among them, the pavement surface temperature had greatest effect on the dependent variable of the model $\left(R^{2}=0.971\right)$.

After determining the correlation coefficients of the parameters, a linear fitting analysis was performed and the results were presented in two equations with the same coefficient of determination $\left(R^{2}=0.964\right)$. Coefficients of independent parameters and also three statistical parameters, including standard error of the coefficients, $\mathrm{t}$-value and significant level (P-value) are also presented in Table 4. Standard error is similar to the standard deviation for a mean. The larger the value, the more spread out the points are from the regression line. The more spread out the points are, the less likely that significance will be found. The next parameter, $t$-value is the test statistic calculated for the individual predictor variable. This is used to calculate the P-value. P-value is the probability level (p). This tells whether or not an individual variable significantly predicts the dependent variable. Typically, if the P-value is below 0.050 , the value is considered significant.

The calculated value of coefficient $\beta_{4}$ was 1.096 for Model 1; while its standard error (0.909) was high and resulted in a reduction of $\mathrm{t}$-value. In this model, the coefficient $\beta_{4}$, with a $P$-value of 0.229 , indicates that there is no significant level with probability above $95 \%$ associated with the dependent variable. To avoid this, $\beta_{4}$ was removed and linear fitting analysis was conducted again without this coefficient.

New coefficients of modified BELLS model are presented as Model 2 in Table 4. In the proposed model, the coefficients were modified and $t$-values were increased in all variables. According to the P-values, it is clear that the significant level of all coefficients of the model are above $95 \%$. Hence, for the structural evaluation of new pavements, it is proposed to determine the depth temperature of asphalt layers using the new version of BELLS model, as presented in Eqn (3):

$$
\begin{aligned}
& T_{d}=1.725+1.022 \times I R+[\log (d)-1.25] \\
& {\left[-0.419 \times I R+0.491 \times T_{(1-\text { day })}+0.054 \times I R \sin \left(h r_{18}-13.5\right)\right],}
\end{aligned}
$$

where all parameters were defined earlier in Eqn (1). Figure 10 shows the predicted depth temperatures of the 


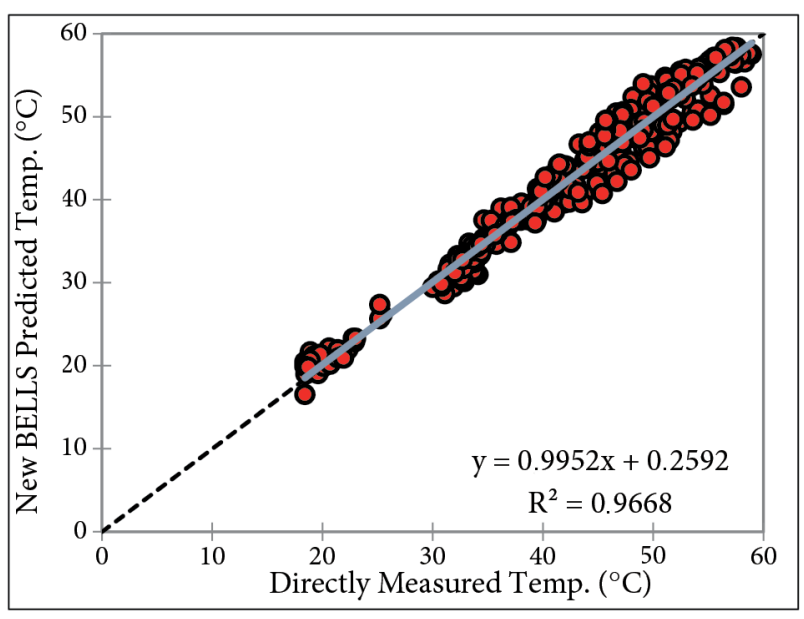

Figure 10. New BELLS model predicted versus directly measured temperatures in new pavements

asphalt layers using this new BELLS model versus measured values in new pavements. According to this figure, the coefficient of determination is about 0.97 , the slope and intercept of the trend line are close to 1 and zero, respectively. Hence, accuracy of the model was increased significantly. This model can be used for analysis of new pavements located in hot climate areas where the asphalt layers experience temperatures up to $59^{\circ} \mathrm{C}$.

\section{Conclusions}

Based on pavement temperature variation analysis that was performed in this research, the following conclusions can be drawn:

- Temperature measurements of FWD device although is straight forward, has several drawbacks, including hole drill operation is time consuming; It may not measure the middle of the asphalt layer due to lack of knowledge of total thickness of the asphalt layers; Depth temperature of asphalt layers are extended to all sections before the next temperature measurement.

- AASHTO and BELLS methods can be used to estimate the depth temperature of asphalt layers without interrupting FWD testing. These methods have several advantages compared with the direct measurement. BELLS model requires less data. In fact, it uses mean air temperature of previous day of testing instead of 5-day air temperatures in AASHTO method.

- The measured and predicted temperatures in rehabilitated pavements showed high correlations, exhibited a coefficient of determination of 0.98 and RMSE of 1.096. Hence, reliable prediction of depth temperature can be achieved using BELLS model in rehabilitated pavements in hot climate areas.

- RMSE between the measured and predicted temperatures based on BELLS model in new pavements was five times greater than in rehabilitated pavements. In all new pavement sites, BELLS model resulted in lower temperatures than the measured ones, which confirm the inaccuracy of BELLS model in new pavements.

- In the developed new BELLS model, coefficient $\beta_{4}$ was removed because it did not have the required significance level attributed to a high P-value. Finally, a new model was proposed to predict the depth temperature of asphalt layers in new pavements located in hot climate areas with maximum temperature of $59^{\circ} \mathrm{C}$.

\section{References}

AASHTO T317:2009 Prediction of asphalt-bound pavement layer temperatures. American Association of State Highway and Transportation Officials. Washington, D.C., USA, 2009.

AASHTO. 1993. AASHTO guide for design of pavement structures. American Association of State Highway and Transportation Officials. Washington, D.C., USA.

ARA. 2004. Guide for mechanistic-empirical design of new and rehabilitated pavement structures. NCHRP 1-37A, National Cooperative Highway Research Program, Transportation Research Board, National Research Council. Washington, D.C.

ASTM D7228-06a:2015 Standard test method for prediction of asphalt-bound pavement layer temperatures. West Conshohocken, PA., USA. https://doi.org/10.1520/D7228-06AR15

Dakessian, L.; Harfoushian, H.; Habib, D.; Chehab, G. R.; Saad, G.; Srour, I. 2016. Finite element approach to assess the benefits of asphalt solar collectors, Transportation Research Record: Journal of the Transportation Research Board 2575: 79-91. https://doi.org/10.3141/2575-09

Dawson, T.; Baladi, G.; Musunuru, G.; Prohaska, M.; Jiang, Y. J. 2016. Global procedure for temperature adjustment of measured pavement deflection data - Based on the longterm pavement performance seasonal monitoring program, Transportation Research Record: Journal of the Transportation Research Board 2589: 146-153.

https://doi.org/10.3141/2589-16

Deluka-Tibljaš, A.; Šurdonja, S.; Babić, S.; Cuculić, M. 2015. Analysis of urban pavement surface temperatures, The Baltic Journal of Road and Bridge Engineering 10(3): 239-246. https://doi.org/10.3846/bjrbe.2015.30

Dynatest International A/S. 2014. ELMOD user's manual (ELMOD5). Dynatest Engineering A/S, A/S Reg. No. 63.866. Denmark.

Everitt, P. R. 2001. Prediction of asphalt pavement temperatures in South Africa, in $20^{\text {th }}$ Annual South African Transport Conference and Exhibition, 16-20 July 2001, Pretoria, South Africa.

Fernando, E. G.; Liu, W.; Ryu, D. 2001. Development of a procedure for temperature correction of backcalculated AC modulus. Texas Department of Transportation, Research and Technology Implementation Office, FHWA/TX-02/1863-1.

FHWA. 1994. LTPP seasonal monitoring program: Instrumentation installation and data collection guidelines. Report No. FHWA-RD-94-110. McLean, VA.

García, J. A. R.; Castro, M. 2011. Analysis of the temperature influence on flexible pavement deflection, Construction and Building Materials 25(8): 3530-3539.

https://doi.org/10.1016/j.conbuildmat.2011.03.046

Gui, J. G.; Phelan, P. E.; Kaloush, K. E.; Golden, J. S. 2007. Impact of pavement thermophysical properties on surface temperatures, Journal of Materials in Civil Engineering 19(8): 683-690. https://doi.org/10.1061/(ASCE)0899-1561(2007)19:8(683) 
Han, R.; Jin, X.; Glover, C. J. 2011. Modeling pavement temperature for use in binder oxidation models and pavement performance prediction, Journal of Materials in Civil Engineering 23(4): 351-359.

https://doi.org/10.1061/(ASCE)MT.1943-5533.0000169

Inge, E. H.; Kim, Y. R. 1995. Prediction of effective asphalt layer temperature, Transportation Research Record: Journal of the Transportation Research Board 1473: 93-100.

IRIMO. 2016. Climate data reports 1951-2014 I.R. of Iran Meteorological Organization [online], [cited 25 November 2016]. Available from Internet: http://www.irimo.ir/eng/wd/720-Products-Services.html

Kavussi, A.; Solatifar, N.; Abbasghorbani, M. 2016. Mechanistic-empirical analysis of asphalt dynamic modulus for rehabilitation projects in Iran, Journal of Rehabilitation in Civil Engineering 4(1): 18-29. https://doi.org/10.22075/jrce.2016.488

Korczak, R.; Tighe, S.; Cimini, G. 2012. Use of an automated temperature data logger (ATDL) during falling weight deflectometer (FWD) testing, in Conference of the Transportation Association of Canada Fredericton - Advances in Pavement Evaluation and Instrumentation Session, 2012, New Brunswick, Canada.

Luca, J.; Mrawira, D. 2005. New measurement of thermal properties of Superpave asphalt concrete, Journal of Materials in Civil Engineering 17(1): 72-79.

https://doi.org/10.1061/(ASCE)0899-1561(2005)17:1(72)

Petersen, C.; Mahura, A. 2012. Influence of the pavement type on the road surface temperature. Danish Meteorological Institute, Copenhagen, Denmark.

Solatifar, N.; Kavussi, A.; Abbasghorbani, M.; Katicha, S. W. 2017a. Development of dynamic modulus master curves of in-service asphalt layers using MEPDG models, Road Materials and Pavement Design. https://doi.org/10.1080/14680629.2017.1380688

Solatifar, N.; Kavussi, A.; Abbasghorbani, M.; Sivilevičius, H. 2017b. Application of FWD data in developing dynamic modulus master curves of in-service asphalt layers, Journal of Civil Engineering and Management 23(5): 661-671. https://doi.org/10.3846/13923730.2017.1292948

Stubstad, R. N.; Baltzer, S.; Lukanen, E. O.; Ertman-Larsen, H. J. 1994. Prediction of AC mat temperatures for routine loaddeflection measurements, in $4^{\text {th }}$ International Conference on the Bearing Capacity of Roads and Airfields, 1994, Minneapolis, Minnesota, USA.

Vasenev, A.; Hartmann, T.; Dorée, A. 2012. Prediction of the in-asphalt temperature for road construction operations, in International Conference on Computing in Civil Engineering, 17-20 June 2012, Clearwater Beach, Florida, USA. https://doi.org/10.1061/9780784412343.0059

Wang, D. 2016. Prediction of time-dependent temperature distribution within the pavement surface layer during FWD testing, Journal of Transportation Engineering 142(7): 06016002. https://doi.org/10.1061/(ASCE)TE.1943-5436.0000854

Wang, Y.; Zhu, S.; Wong, A. S. T. 2014. Cooling time estimation of newly placed hot-mix asphalt pavement in different weather conditions, Journal of Construction Engineering and Management 140(5): 04014009.

https://doi.org/10.1061/(ASCE)CO.1943-7862.0000832 